\section{CONTRIBUTION TO THE STUDY OF PARALDEHYDE.}

BY JOHN GORDON, M.D.,

Assistent to the Professor of Materia Medica, University of Aberdeen; Assistant Surgeon to the Sick Children's Hospital, Aberdeen; Physician to Aberdeen General Dispensary.

THE clinical aspects of paraldehyde have now been under observation for several years, and reports on some of its actions have been published by various observers, who have given the drug a trial in suitable cases.

It was introduced by Dr. Cervello, of Palermo, about 1883. Its use as a valuable hypnotic has been claimed in cases of sleeplessness following such acute diseases as croupous pneumonia, bronchitis, and various heart diseases, as well as in the insomnia of nervous irritability or overwork, and also in cases of cerebral disease-for example, mania and hypochondriasis. The sleep which it induces is said to be prompt, tranquil, and prolonged; there is no stage of excitement preceding its action, and during sleep the patient can easily be brought round without any feeling of stupidity, while there is no headache, nor disordered digestion, nor period of depression.

Over hydrate of chloral the advantages claimed are that it diminishes the frequency of the heart's contractions, and at the same time strengthens the beats; that it does not cause the diminished blood-pressure which hydrate of chloral produces, and that its action on the respiration is to diminish its frequency.

It seemed, however, that certain points regarding its hypnotic action, as well as its influence in causing increase or decrease of the amount of urine, and its effects on the excretion of the nitrogenous constituents of urine and the chlorides, had not been investigated, and it was with reference to these points that part of the following investigations and experiments were conducted.

It also seemed desirable, so as to complete the pharmacology of the drug under observation, to undertake a series of experiments and investigations to ascertain its influence on sensory and motor nerves, on the functions of the spinal cord, as well as on muscle substance itself, and to observe its action on blood-pressure and respiration.

Paraldehyde has the formula $\mathrm{C}_{6} \mathrm{H}_{12} \mathrm{O}_{3}$. It is a polymeric form of aldehyde, and its formula may be looked on as a combination of three molecules of aldehyde; thus $\mathrm{C}_{2} \mathrm{H}_{4} \mathrm{O}=$ aldehyde. $\left(\mathrm{C}_{2} \mathrm{H}_{4} \mathrm{O}\right)_{3}$ $=\mathrm{C}_{6} \mathrm{H}_{12} \mathrm{O}_{3}=$ paraldehyde. It is obtained by the action of concentrated sulphuric acid on aldehyde, which causes the liquid to become warm. On cooling to $0^{\circ} \mathrm{C}$., the paraldehyde separates as crystals. At ordinary temperatures it is a transparent, colourless, volatile fluid. $\Delta t 10^{\circ} \mathrm{C}$. it passes into crystalline form, and it boils at $124^{\circ} \mathrm{C}$. Its specific gravity at $15^{\circ} \mathrm{C}$. is 0.998 . Its odour is like that of parsley, while its taste is pungent and somewhat disagreeable.

The drug is largely given off by the lungs, for its odour may easily be detected in the breath six or eight hours after taking it, and following the administration of large doses (60 minims), I have noticed its odour in the urine excreted three or four hours after the dose. When added to water it separates into oily-looking globules, but these readily disappear on shaking. It is soluble in about eight parts of cold water, is still more soluble in hot water, and can be dissolved in all proportions in alcohol or ether.

Description of the Methods followed in the Estimation of Urine and its Constituents.-Six boys were selected for the purpose of the experiments; they had suffered from some trifling surgical affection, but had quite recovered at the time when the observations began. One was under observation at a time. Three of the boys yielded results sufficiently complete to allow of their publication; the other three, from various causes, failed to complete the experiments. Frach boy, during the period of observation was supplied with an ordinary mixed diet, such as he preferred and was in the habit of taking, and this selected diet was continued during the whole time of the experiments, no extras being allowed. The solids of the diet were carefully weighed and the fluids accurately measured. He was kept in bed when under the influence of the drug; at other times he was allowed moderate exercise in the wards of the hospital (Aberdeen Sick Children's) where the observations were made. The total quantity of urine passed was carefully collected; that which was excreted between the hours of 9 A.M. and 9 P.M. was called "day urine," and that which was passed from 9 P.M. to 9 A.M. was known as "night urine." The measurement of each quantity of urine is given in cubic centimètres; its specitic gravity is noted; so also is its reaction on litmus paper, and the appearance and odour of the quantity examined. For the estimation of the urea Russell and West's apparatus was employed. This process consists in using a freshly prepared solution of sodium hypobromate to decompose the urea, and measuring the nitrogen liberated in the decomposition.

The chlorides were ascertained by volumetric analysis. A standardised solution of mercuric nitrate was used, the working strength being 1 cubic centimètre of solution $=0.01$ gramme $\mathrm{NaCl}$. In most of the estimations, both of the urea and the chlorides, duplicate observations were made for the purpose of control. The estimation of the "day" and "night" urine was made separately. The measurement of the total quantities of the "day" and "night" urine was carefully done, and is recorded in cubic centimètres. The reaction to litmus paper was observed at the time of excretion, and the odour noted at the period of passing. The boys being healthy and good sleepers, and as one object of the experiments was to observe what effect paraldehyde had as a hypnotic in ordinary health, it was thought best to give the dose of the drug in the morning about 9 o'clock. The dose was always administered well mixed and diluted in water.

The temperature, pulse, and respirations were taken on the days of the administration of the drug, immediately before the dose, half an hour after the dose, and also two hours later. The state of the skin was observed, the behaviour of the subject as regarded sleep, and the effects of the drug on appetite and digestion.

Some days before the first dose was given the subject was put on his regulated diet, the urine collected and measured, its reaction, appearance, and odour noted, and its urea and chlorides estimated; and as soon as a steady, or an approximation to a steady, condition of the constituents of urine was obtained, the dose of the medicine was supplied. This morning dose was continued in the first two recorded cases for three consecutive mornings; then followed a period of three days' freedom from the paraldehyde; this period was again succeeded by another three days' administration of the drug in an increased dose; then the three days' rest or freedom from the drug took place; and so on till the experiment was completed.

The only difference in Case III is that the periods of administration and exemption were at intervals of two days. In order to facilitate the understanding of the methods followed and the results obtained, I have drawn up a daily journal of each case, and have furnished charts showing the amounts of the excretions. In the three recorded cases the diet was quite the same in the amounts of its solid and liquid ingredients, and was as follows:

\begin{tabular}{|c|c|c|c|c|c|c|}
\hline \multirow{4}{*}{ Breakfast } & & & \multicolumn{2}{|c|}{ Grammes. } & \multicolumn{2}{|c|}{ Cubic centimètre } \\
\hline & Porridge & ... & ... & 232.0 & ... & - \\
\hline & Bread & $\ldots$ & $\ldots$ & 43.6 & ... & \\
\hline & Milk & $\ldots$ & $\ldots$ & - & ... & 365 \\
\hline & Soup & $\ldots$ & $\ldots$ & - & ... & \\
\hline Dinner & Bread & $\ldots$ & $\ldots$ & 43.6 & ... & - \\
\hline Dinner & Beef & $\ldots$ & $\ldots$ & 73.0 & ... & - \\
\hline & Potatoes & $\cdots$ & $\ldots$ & 43.6 & $\cdots$ & 365 \\
\hline Sinner & Milk & $\cdots$ & $\cdots$ & $\overline{870}$ & $\cdots$ & 000 \\
\hline Supper & Bread & $\cdots$ & $\cdots$ & $\begin{array}{l}87.0 \\
44.0\end{array}$ & $\cdots$ & $\div$ \\
\hline & Water & $\ldots$ & $\ldots$ & - & $\ldots$ & 300 \\
\hline & Tota &.. & ... & 566.6 & ... &, 268 \\
\hline
\end{tabular}

I have selected one case as typical of the others, and give its records fully, namely, Case IIr. In all the chief features of investigation the other two cases showed similar results. 
Darly Journal of Cage iII: J. W., aged 10 Years.

\begin{tabular}{|c|c|c|c|c|c|c|c|c|c|c|c|c|c|}
\hline \multirow{2}{*}{ Date. } & \multirow{2}{*}{$\begin{array}{l}\text { Paral- } \\
\text { dehyde } \\
\text { dosage. }\end{array}$} & \multirow{2}{*}{ 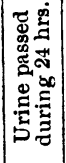 } & \multirow{2}{*}{$\begin{array}{l}\text { Appear- } \\
\text { ance. }\end{array}$} & \multirow{2}{*}{$\begin{array}{c}\text { Odour } \\
\text { of } \\
\text { paral- } \\
\text { dehyde. }\end{array} \mid$} & \multirow{2}{*}{$\begin{array}{l}\text { Spe- } \\
\text { cific } \\
\text { gra- } \\
\text { vity. }\end{array}$} & \multirow[b]{2}{*}{ Urea. } & \multirow{2}{*}{$\begin{array}{l}\text { Chlo- } \\
\text { rides. }\end{array}$} & \multicolumn{3}{|c|}{ Pulse. } & \multicolumn{3}{|c|}{$\begin{array}{c}\text { Respira- } \\
\text { tions. }\end{array}$} \\
\hline & & & & & & & & & \begin{tabular}{c|} 
\\
0 \\
0 \\
0 \\
$\vdots$ \\
0
\end{tabular} & $\begin{array}{r}5 \\
\vdots \\
-1 \\
-7\end{array}$ & $\begin{array}{l}0 \\
\dot{a} \\
0 \\
0\end{array}$ & $\begin{array}{l}5 \\
\vdots \\
0 \\
0 \\
0\end{array}$ & : \\
\hline 1 & & a & & & & $\mathrm{ms}$ & & & & & & & \\
\hline & None & $\begin{array}{l}1560 \\
1070 \\
1\end{array}$ & $\begin{array}{c}\text { Normal } \\
"\end{array}$ & None & $\begin{array}{l}1028 \\
1018\end{array}$ & \begin{tabular}{|l|}
6.2 \\
4.7
\end{tabular} & $\begin{array}{l}6.4 \\
7.2\end{array}$ & ב & $\overline{-}$ & - & - & 二 & 0 \\
\hline & $m x$ & 1280 & $\begin{array}{c}\text { Trace of } \\
\text { urates }\end{array}$ & " & 1022 & 7.8 & 8.9 & 80 & 92 & 90 & 24 & 24 & 24 \\
\hline ", & Non & 1370 & Normal & ", & 1026 & 7.0 & 9.0 & 80 & 90 & 84 & 2 & 20 & 24 \\
\hline $\begin{array}{ll}\prime \prime & 1\end{array}$ & None & $\begin{array}{r}1420 \\
770\end{array}$ & $\begin{array}{l}\text { Urates } \\
\text { Uric }\end{array}$ & ", & $\begin{array}{l}1022 \\
1024\end{array}$ & $\begin{array}{l}8.0 \\
6.0\end{array}$ & $\begin{array}{r}11.0 \\
5.2\end{array}$ & 二 & ב & Z & $=$ & - & - \\
\hline & $\mathfrak{m} \mathbf{x x}$ & 1030 & Normal & & 1020 & 8.4 & 7.2 & 92 & 96 & 90 & 24 & 22 & 20 \\
\hline & " & 1070 & $\mathbf{U r i}$ & ", & 1018 & 6.8 & 8.5 & 80 & 80 & 76 & 24 & 20 & 24 \\
\hline & None & 1440 & Normal & 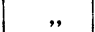 & 1020 & 8.4 & 11.9 & - & - & - & - & - & - \\
\hline & & 1080 & & " & 1018 & 7. & 7.6 & - & - & - & - & -1 & $\overline{0}$ \\
\hline & $\mathbf{x l}$ & 1560 & $\begin{array}{l}\text { Uric } \\
\text { acid }\end{array}$ & Slight & 1020 & 6.5 & 6.4 & 92 & 80 & 72 & 20 & 24 & 20 \\
\hline ", & & 1230 & Normal & & 1020 & 5.6 & 7.4 & 92 & 72 & 84 & 24 & 24 & 20 \\
\hline & None & $\begin{array}{l}14+5 \\
1220\end{array} \mid$ & Urates & None & $\begin{array}{l}1018 \\
1017\end{array}$ & 2.6 & $\begin{array}{l}9.3 \\
8.9\end{array}$ & 二 & ב & 二 & ב & 1 & - \\
\hline & $\mathrm{mix}$ & 1270 & Normal & Marked & 1018 & 3.9 & 8.1 & 90 & 76 & 80 & 24 & 20 & 19 \\
\hline & Non & 1100 & 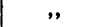 & & 1018 & 6.4 & 6.8 & 80 & 72 & 84 & 24 & 20 & 20 \\
\hline & None & $\begin{array}{l}1350 \\
1450\end{array}$ & " & ne & $\begin{array}{l}1026 \\
1022\end{array}$ & 5. & $\begin{array}{l}8.7 \\
8.0\end{array}$ & - & ב & $\exists$ & Z & $=$ & 二 \\
\hline & m loxx & 1500 & ", & Mark̉ed & $\begin{array}{l}1026 \\
1018\end{array}$ & $\begin{array}{l}6.0 \\
6.5\end{array}$ & 13.0 & 88 & 76 & 88 & 24 & 20 & 20 \\
\hline$"$ & $"$ & 11 & ", & Ver & 1016 & 5.5 & 8.0 & 84 & 80 & 92 & 24 & 20 & 21 \\
\hline June & None & 910 & & None & 1024 & 3. & 7.4 & - & -1 & - & - & - & - \\
\hline$"$ & & 1180 & $m$ & 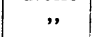 & 1022 & 4. & 7.4 & 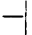 & 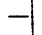 & 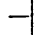 & 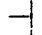 & - & 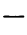 \\
\hline
\end{tabular}
Temperature normal.

Further Clinical Observations on CASE III.-1. Hypnotic Effects:- No evidence of any hypnotic action of the drug was noticed till the administration of the dose of 40 minims. This dose was followed in half an hour by a sleep of 40 minutes. After the next dose of 40 minims there was evidence of drowsiness for a short time, with flushing of the face, but no sleep followed. On May 27th, under a dose of 60 minims, half an hour of sleep was induced. A dose of 80 minims given on May 30th failed to cause sleep, but, after a similar dose on the following day, he was drowsy for an hour.

2. Effects on Digestion:- Shortly after the administration of the second dose of paraldehyde in this case, a slightly relaxed condition of the bowels took place ; it did not quite reach diarrhœe, but loose motions were passed twice or sometimes thrice a day, and this condition was always marked on the days when the paraldehyde was given. The stools were dark and slightly offensive. This relaxed condition alternated at times with a day or two of constipation, when no paraldehyde was given. It would seem, therefore, that the drug in this case had a tendency to induce diarrhoea, but it did not appear that the size of the dose had any marked effect, for the relaxed condition was as evident under the small doses as under the large. None of the other cases showed this tendency to diarrhoea under the influence of the drug. The appetite was not affected, neither was pain complained of in stomach nor bowels.

3. Effects on the Skin :-During the experiment the skin was always dry, both while the drug was administered and when it was withheld. Both with the smaller and larger doses there was a marked tendency to flushings of the face, which continued for an hour or more. This was also noticed in the other cases experimented on.

4. Effects on the Temperature:-The temperature, which was taken in the axilla and in the rectum half an hour before the administration of the drug, and at intervals of an hour after the dose till the odour of the drug was no longer noticed in the breath, did not show any marked rise or fall. A few continuous temperatures were also taken in the axilla, but they did not show any point of interest.

5. Excretion of Urea:-As has already been mentioned, the treatment of this case varied from that of the others to the extent that he was subjected to two days' consecutive administration of paraldehyde, followed by two days' freedom from it. After the first few doses of the medicine a somewhat relaxed condition of the bowels took place, and this was always most marked on the days in which the drug was given. It has to be remembered that there is a pos- sibility that some of the urea may have been excreted by the bowels, and that this may to some extent explain the small quantities of urea excreted on some of the days on which a large dose of paraldehyde was given. In this case, as in all the other cases, the greatest activity in the excretion of urea was under the influence of the smaller doses. The maximum day's excretion was 8.4 grammes, and this followed a dose of 20 minims. The next greatest was 7.8 grammes, after a dose of 10 minims. The lowest excretion in one day followed a dose of 60 minims, namely, 5 grammes. The highest two days' excretions were 15.2 grammes, the daily dose being 20 minims; while the smallest two days' excretion in this experiment was 10.3 grammes, the daily dose being 60 minims. The total quantities of urea excreted under the influence of the drug were 64.4 grammes. The total quantities without paraldehyde were 56.3 grammes, or an increase with paraldehyde of 8.1 grammes.

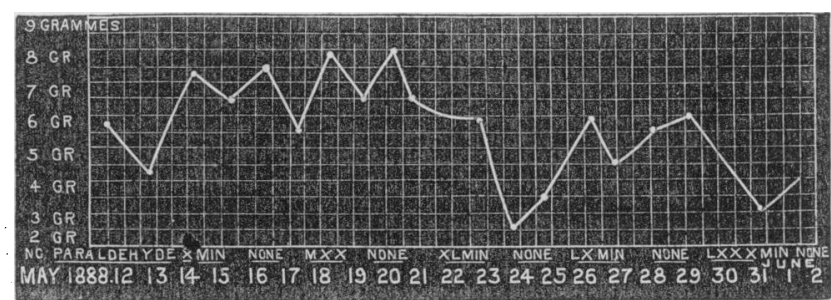

Chart 1.-Case 1II. Urea chart. May 12th, 1888, to June 2nd, 1888. Daily quantity of urea excreted is expressed in grammes. Paraldehyde was given on two consecutive days, followed by two days' freedom from the drug.

Excretion of Chlorides.-I have been unable to trace any definite connection as to the steady increase or decrease of the weights of the chlorides excreted during the administration of the paraldehyde in the three cases that I record; thus :

CASE I:

Total quantities of chlorides passed in 12 days during administration of paraldehyde $\ldots$ without paraldehyde

Grammee. 127.0

Increase with paraldehyde ...

CASE II :

Total quantity of chlorides passed in 12 days with paraldehyde

Total quantity passed in 12 days without paraldehyde

Decrease with paraldehyde ...

CASE III:

Total quantity of chlorides passed in 10 days with paraldehyde...

Total quantity of chlorides passed $\dddot{\ldots} 10$ days without paraldehyde $\quad \ldots \quad \ldots$...

100.0

Increase with paraldehyde ...

Quantity of Urine Excreted.-My observations point to somewhat different conclusions from those of a number of other observers, who state that there is always a marked increase of the fluid constituents of the urine following the administration of paraldehyde. I have found that the quantity of urine after doses of paraldehyde is not always increased.

Thus, in CASE Ir :

Cubic

The total quantity of urine passed in 12 days during which paraldehyde was given was ...

The total quantity in a like number of days without paraldehyde was ...

Centimètres.

12,531

14,333

Or a decrease with paraldehyde of $\ldots \quad \quad \ldots \quad \overline{1,802}$

Also, in CASE IIr :

The total quantity of urine passed in 10 days with paraldehyde was ... $\begin{array}{llll}\text { without paraldehyde was ... } \quad \ldots & \ldots\end{array}$

Or a decrease with paraldehyde of $\ldots \quad \ldots$ 
But in CASE $\mathbf{r}$ :

The total quantity of urine passed in 12 days with paraldehyde was $\quad \ldots \quad \ldots \quad$...

The total quantity without was $\quad \ldots \quad \ldots \quad \ldots \quad 12,838$

Oran increase with paraldehyde of ... $\quad \ldots \quad 1,670$

With results such as these, obtained from the three above completed cases, it would be unsafe to draw any general conclusion; but it is quite evident that, at any rate, in cases of average health, it does not invariably follow that administration of paraldehyde for a given period increases the quantity of the fluid constituents of urine, and that cases occur in which its administration for a considerable time is followed by a greater or less diminution of urine.

Odour in Urine.-There is no doubt that a considerable proportion of paraldehyde is excreted by the lungs, as it may easily be detected in the breath; yet when a large dose (say, 40 minims or more) is given, an odour much akin to paraldehyde is distinctly evident in the urine, indicating that a portion of the drug is excreted by the kidneys, and possibly only slightly modified. The earliest time at which I detected this odour in the urine after the dose of the drug was four hours. From the presence of paraldehyde in almost an unchanged condition in the urine, and the observation that it has an influence in controlling pain, I was led to suppose that it would have some sedative action in irritation of the bladder. And as the result of clinical observation I have found that it has this influence in some cases when prescribed in large doses.

Blood-Pressure and Respiration.-A number of kymographic experiments on blood-pressure and respiration were performed on cats and rabbits, and the following conclusions were formed:-1. There is no marked fall in the blood-pressure as the result of the small doses, when the absorption of the drug takes place gradually, as following hypodermic injection. 2. That the fall in the blood-pressure is only evident after large doses, and that this fall is always secondary to the diminished respiration which its action produces. 3. That intra-venous injection causes a rapidly fatal result, the drug thus reaching the heart in a large quantity at one time. 4. That the respirations are slowed. 5. That death always took place by paralysis of respiration. 6. That although under Experimant C.-Cat under Ether.

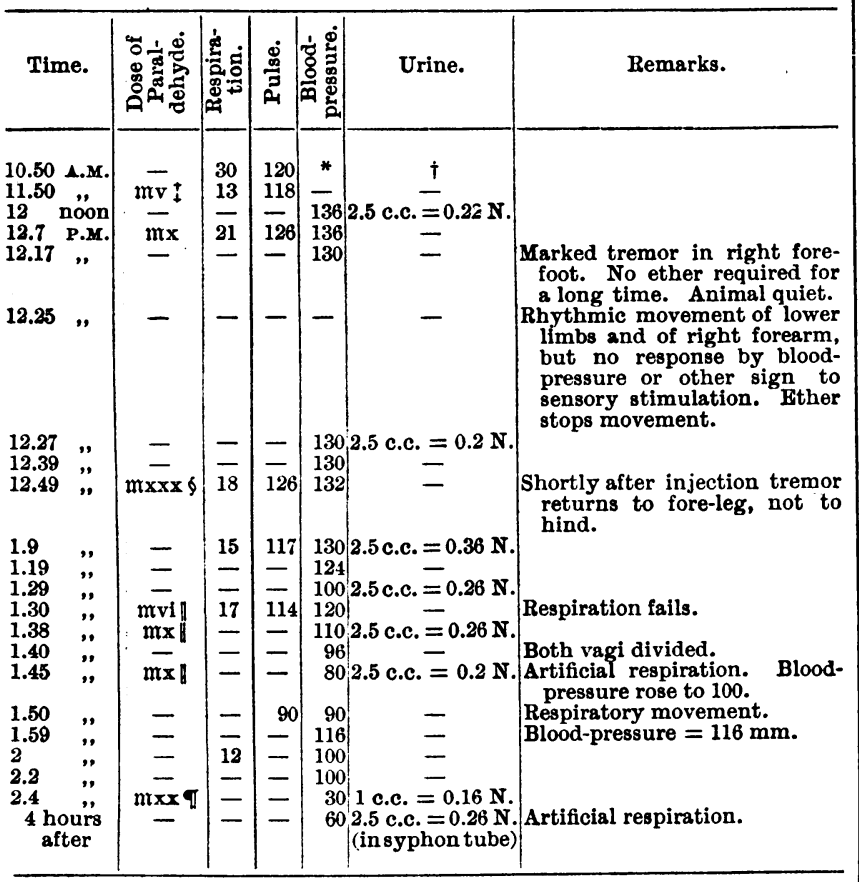

* Varied in an hour before paraldehyde from 144 to 132.

t 2.5 c.c. excreted in an hour before injection $=0.45 \mathrm{~N}$

IDissolved in salt solution. Injected in divided doses below skin of thorax Into left femoral vein.

the influence of smaller doses, respiration,was distinctly slowed, there was no danger of failure of respiration, and that only with large doses (two grammes to a cat) was a dangerous dos 6 reached. 7. That the pulse was slowed, and its beats made stronger.

I give the observations and records of one experiment in full.

Action of Paraldehyde on Reflex Functions of the Spinal Cord. -A number of experiments were performed to elucidate this part of the subject of study. The method followed was to destroy the cerebral lobes of a frog; to wait till the shock of the decerebration had been so far recovered from, to expose and ligature the iliac artery and vein of one limb; to suspend the frog by the head, allowing the hind limbs to hang down free; to immerse the hind limbs alternately, or both together, in a solution of sulphuric acid, 3 th, and to record the time of withdrawal or movement of the limb or limbs from the fluid by a metronome. The limbs after withdrawal were washed in water. When the time of withdrawal was about constant in both limbs, a dose of paraldehyde was injected below the skin of the thorax, and the immersion continued as before.

As the result of these experiments, it was found that there was a longer lapse of time between the application of the stimulus and the reflex action, when paraldehyde had been administered, thus showing a diminished excitability in the cord; and that it also had a peripheral action on the sensory nerves, as was shown by the elongation of the period at which the unligatured limb was withdrawn from the stimulus.

It was also observed that the reflex action might be quite abolished with the dose of paraldehyde; but if the frog was kept carefully moist with salt solution, very considerable recovery of the reflex action was obtained twenty-four hours after, and in some forty-eight hours after the first injection. The frogs, however, in all cases ultimately died.

Action of Paraldehyde on Motor Nerves.-As the results of a large number of experiments performed on the sciatic nerves of frogs, it was noticed that the nerve soon lost its irritability, that the irritability could so far be recovered by subsequent washings of the nerve, as could be done with muscle, and also that the nerve lost its irritability sooner than the muscle, and with a smaller dose of the drug. The following is a record of one of these experiments.

The sciatic nerve of a frog was immersed in a solution of $1 \frac{1}{2}$ minim of paraldehyde dissolved in salt solution. Stimulation was applied every three minutes with the du Bois-Reymond's coil at 6 centimettres. The paraldehyde solution was added to the nerve (which had previously given a good contraction on stimulation) at 11.57 A.M.

$$
\begin{aligned}
& \text { At } 12 \text { a good response on stimulation } \\
& \text { "12.3 fe" } 12.6 \text { feeble response } \\
& \text { " 12.9 very feeble response } \\
& \text { " } 12.12 \text { " } 12.15 \text { no reponse. }
\end{aligned}
$$

The coil was now approximated to 4 centimètres. No response. Next to 0 centimètres; still no response. The muscle (gastroenemius) which was immersed in a solution of the same strength, on repeated stimulation did not lose its irritability. The nerve was then carefully washed with normal salt solution, and again stimulated, but no response was got.

Action of Paraldehyde on Muscle Substance.-The apparatus employed in these experiments included the muscle chamber invented by Professor Cash, and fully described by him in his paper, entitled, "Contributions to our Knowledge of the Connection between Chemical Constitution, Physiological Action, and Antagonism." Three sets of muscle experiments were made, namely :-1. Immersion of the muscle in paraldehyde solution, and single stimulations given to test the action of the drug on the irritability of muscle. 2. Where the faradic current was employed to test muscular irritability. 3. Where the effects of single stimuli were contrasted in curarised and in non-curarised muscle in the presence of paraldehyde. A large number of experiments were performed to test the irritability of muscle by singlestimuli, and the conclusions arrived at were:-1. That in many cases the first effect following the immersion of the muscle in a small dose of paraldehyde (namely, 1 minim in 50 cubic centimètres salt solution) was to cause an initial increase of irritability in the muscle. 2. That after the first or second set of stimuli this initial rise gave place to a decrease of irritability. 3. That this decrease was frequently, nearly always, partially recovered from. 4. That the effect of a large dose of paraldehyde (5 or 10 minims 1 Phil. Trans. of the Royal Society, part i, pp. 231-32, 1894. 
in 50 cubic centimètres salt solution) was to cause a rapid loss of irritability in the muscle, which was only very slightly recovered from by subsequent washing in salt solution.

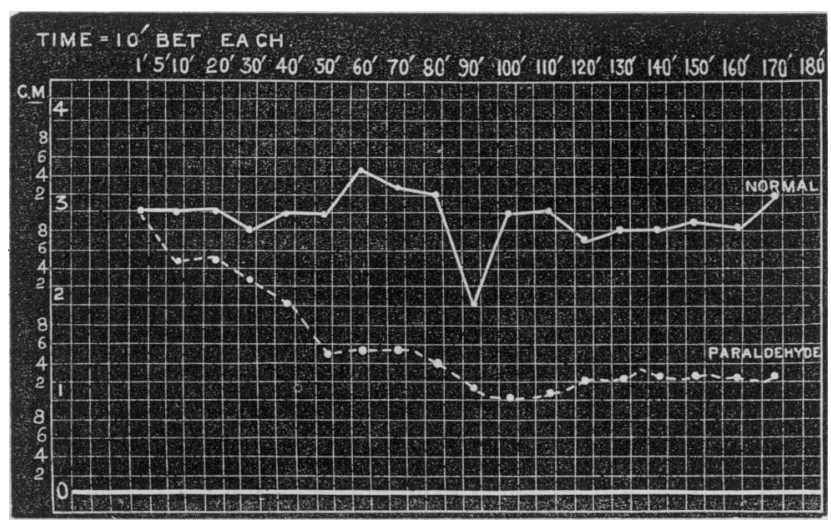

Chart 2.-Contrasting action of a small dose $\left(2 \frac{1}{\mathrm{~m}} \mathrm{~m} .=50\right.$ c.c. salt solution, per cent.) of paraldehyde with normal muscle. Gastrocnemii of frog. Coll $=7.5 \mathrm{~cm}$.

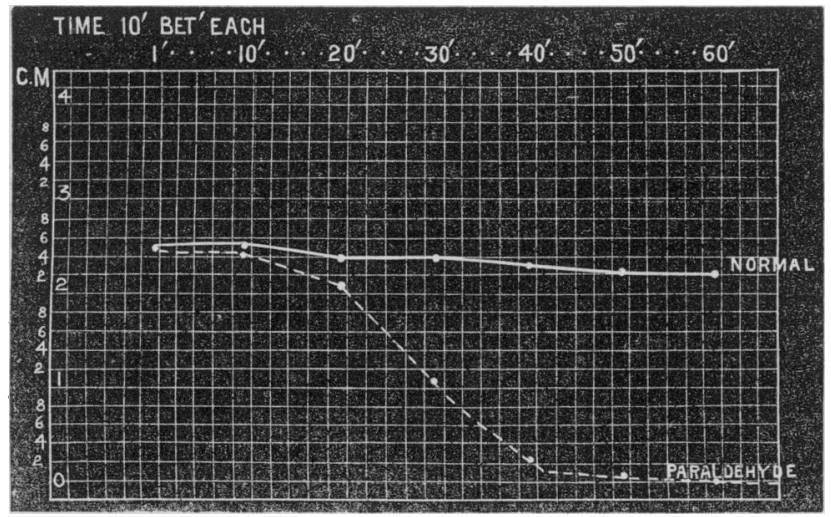

Chart 3.-Contrasting effect of a large dose $(10 \mathrm{~m} .=50$ c.c. salt solution $\frac{3}{4}$ per cent.) of paraldehyde, with normal muscle in salt solution (normal).

Effect of Faradic Current on Muscular Irritability.-The result of these experiments was to show that paraldehyde, especially in large doses (namely, 1 cubic centimètre) quickly abolished the normal tetanic curve, and that a condition of clonus was substituted, which, on further stimulation at definite intervals, became still weaker, and, finally, no response on stimulation was obtained. It was further proved that if the muscle which had failed to respond to stimulation were at that period rapidly washed in salt solution, and reimmersed for fifteen minutes in salt solution, and again stimulated, the irritability of the muscle was, to a certain extent, recovered. When the same muscle was reimmersed in paraldehyde solution for ten minutes, the irritability was once more reduced, and then abolished.

Action of Paraldehyde on Curarised and Non-curarised Muscle. -With the object of ascertaining whether the initial rise of irritability which I observed frequently followed the first application of the solution of paraldehyde in small doses was due to the muscle substance itself, or to the sensory nerves supplying the muscle, a series of experiments with curarised muscle was undertaken. A frog having been pithed, and the blood-supply from one limb having been cut off by a ligature, a dose of curare was injected below the skin of the thorax. When reflex action was quite abolished, the gastrocnemii were dissected out, the one from the ligatured limb representing the non-curarised muscle, the other the curarised. The result of these experiments showed that the curarised muscle gave the greater response to stimulation in presence of the same strength of paraldehyde solution, showing its greater irritability. It was thus evident that the presence of the sensory nerves in the muscle did not explain the initial rise of irritability which took place in the cases mentioned, but that the excitability seemed to depend on the muscle substance itself.
Tetarus Curves.- Faradic stimulation with coil at $7.2 \mathrm{~cm}$. Muenle immersed in $\frac{1}{2}$ c.c. paraldehyde in 50 c.c. salt solution, $\frac{3}{7}$ per cent.

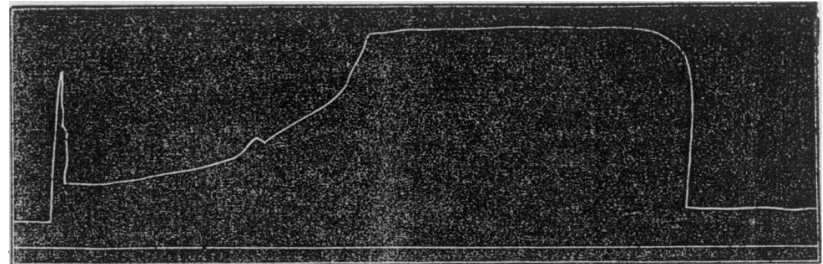

Chart 4.-Tetanus after $30^{\prime}$ immersion in normal eal solution.

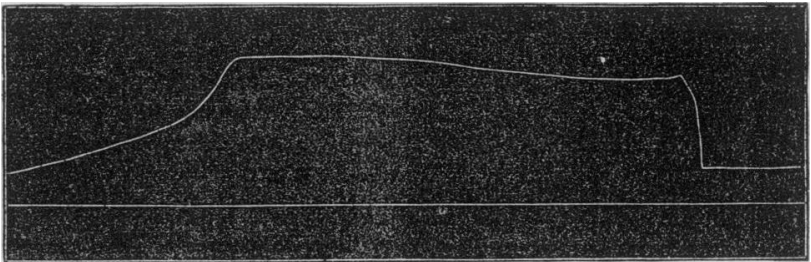

Chart 5.-Lowering of curve after $10^{\prime}$ immersion in 0.5 c.c. paraldehyde solution.

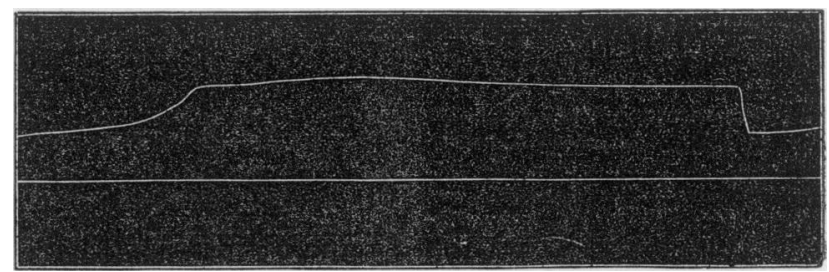

Chart 6.-Greater lowering by a second $10^{\prime}$ immersion in paraldehyde.

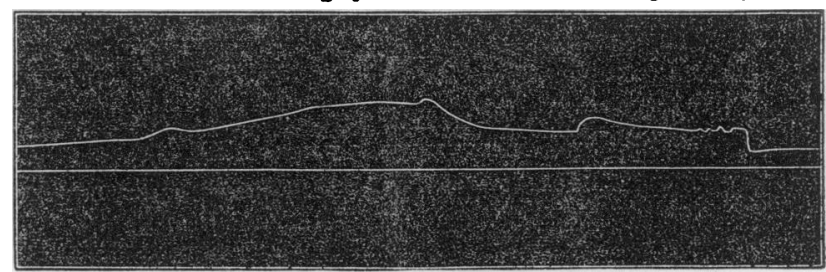

Chart 7.-Feeble rise indicated after third $10^{\prime}$ immersion.

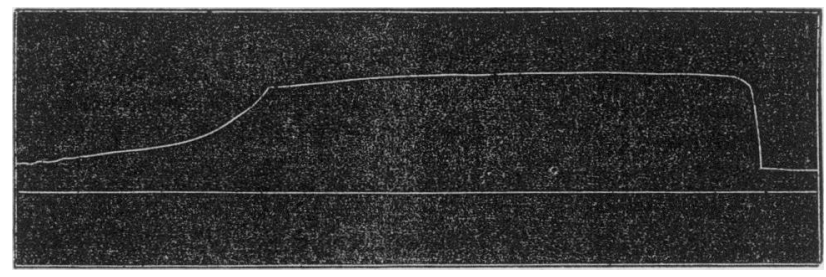

Chart 8.-Increased response obtained after washing with salt solution and immersion in salt solution for $15^{\prime}$.

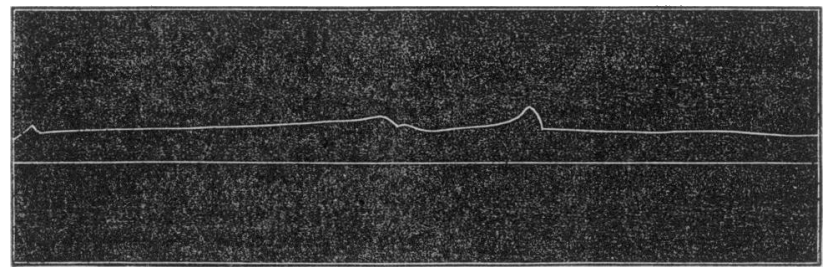

Chart 9.-Response obtained when again treated by immersion for $10^{\prime}$ in 0.5 c.c. paraldehyde solution.

Clinical Observations.-In addition to the experiments that were conducted on the lower animals, the drug was frequently prescribed in cases where I thought it indicated. I found it highly serviceable in cases of insomnia without pain, as, for example, the sleeplessness accompanying heart disease, pneumonia, bronchitis, emphysema, and phthisis. In all these diseases I tried the effects of a full dose, and found the action to be both 
speedy and secure. The patient rapidly passed into a tranquil and refreshing sleep, and awoke without any unpleasant sensations. In overwork followed by loss of sleep I found it extremely valuable, and also in vague nervous ailments with insomnia; and in the hands of other practitioners in like cases they have reported to me very satisfactory results.

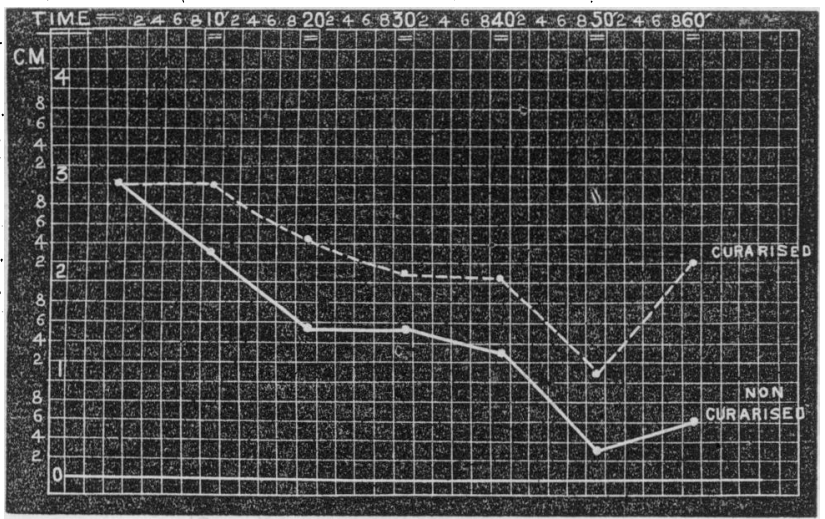

Chart 10.-Contrasting action of paraldehyde on curarised and noncurarised muscle. (Gastrocnemii of frog.) Strength of solution $=1$ minims paraldehyde in 50 c.c. salt solution ( $\frac{3}{4}$ per cent.). Induced current, coil $=4 \mathrm{~cm}$. Height of initial contraction of both muscles $=3 \mathrm{~cm}$. Stimulation every $10^{\prime}$.

The advantages of the drug as a hypnotic, to which group it distinctly belongs, depend on the following points:-(1) It is not a cardiac depressant. (2) It has no marked period of toleration, since in some cases of insomnia from overwork the drug has been taken in the same dose for some months with equally good hypnotic results. (3) No marked craving for the drug seems to be induced by its use. (4) It does not exercise, except in large doses, a hypnotic effect on a person not suffering from sleeplessness; hence there is no probability of its abuse. (5) It has not a marked period of excitement before the hypnotic action takes place. (6) Its action is speedy, patients generally falling asleep within ten minutes after its administration. (7) The patients may be aroused while under its influence without any disagreeable or confused sensations. (8) The sleep which it produces is tranquil and quiet, with diminished respirations; this slowing of the respirations in many pulmonary diseases is of distinct advantage. (9) It is not liable to disorder the digestion. (10) In many cases it is gently laxative in its action. From the experiments which were performed on the lower animals its use as a narcotic in cases of insomnia with slight pain is not contra-indicated, since my experiments with frogs show that it controls to some extent the sensory nerves; and the experiments with cats prove that in large but non-poisonous doses it exercises a narcotic influence. And it is possible that, since a large amount of the drug is excreted by the lungs, its vapour may exercise a narcotic influence on the terminations of the sensory nerves of the lung-tissue while it is being expired.

In one case of incipient phthisis, where its hypnotic action was accompanied by a somewhat profuse perspiration, I found that the addition of a minimum dose of atropine controlled that condition. In only one of the cases in which I prescribed the drug was gastric disturbance noticed. This patient, who suffered from phthisis, complained of a feeling of flatulence, and a disagreeable taste, as of pine-wood.

No loss of appetite followed its use in mv cases, nor headache, nor thirst. The dose I found most serviceable for adults was from 45 to 60 minims. My method of prescribing it was to well dilute it with cinnamon water, adding a little syrup of tolu and compound tincture of cardamoms. Syrup of lemon is also an agreeable combination with it. Some practitioners have observed a beneficial influence from its use in gout and rheumatism, and its action in increasing the excretion of urea from the system may account for the good results in this type of cases; while probably also its narcotic influence on sensory nerves may so far help to explain its action, and I expect that further observations will record its sedative action on the kidneys and bladder.

Summary of Results. - The following is a summary of the results of the experiments and observations detailed in this contribution to the study of paraldehyde.
(1) Paraldehyde caused an increase in the excretion of urea. (2) It did not in any marked way affect the quantities of chlorides excreted. (3) It did not invariably increase the excretion of the fluid constituents of urine, but in the majority of cases which I have recorded it diminished them. (4) The odour of paraldehyde, when given in large doses, was found in the urine, showing that some of it probably passed unchanged through the system. (5) After the full dose of the drug the respirations were slowed, and rendered tranquil and steady. (6) It had no appreciable effect on temperature. (7) In cases of average health without sleeplessness it did not have any hypnotic influence except in large doses. (8) It caused no loss of appetite. (9) There was sometimes a tendency to perspiration under its influence, which atropine controlled. (10) The blood-pressure was only slightly reduced by the smaller doses, the large dose reducing it more, but only after distinct slowing of the respiration. (i1) The pulse was slowed. (12) It diminished the reflex excitability of the spinal cord. (13) It had a peripheral influence in controlling sensation. (14) It speedily diminished, and in large doses destroyed, the irritability of motor nerves. (15) Equal doses diminished the excitability of motor nerves sooner than that of muscle. (16) Small doses first slightly excited and then diminished the excitability of muscle substance. (17) Large doses speedily destroyed (temporarily) the irritability of muscle substance. (18) There was a tendency to complete recovery in the muscle after a small dose, but seldom complete recovery after a large dose. (19) curarised muscle showed increased excitability over non-curarised muscle when treated with an equal dose of paraldehyde and equally stimulated.

In conclusion, I have to express my deep sense of obligation to Professor Cash for the freedom of his laboratory, for the unstinted use of his apparatus, as well as for the many valuable suggestions and directions he gave $m e$ at all times during $m y$ researches on this subject, and also for his performance of the needful operations during $\mathrm{my}$ investigations.

\section{ABSTRACTS OF}

\section{THE HUNTERIAN LECTURES}

\section{PAST AND PRESENT SURGERY.} Delivered at St. G'eorge's Hospital.

BY TIMOTHY HOLMES, M.A.CANTAB., F.R.C.S., Consulting Surgeon to St. George's Hospital.

LECTURE II.

THE lecturer commenced by deprecating exaggerated expectations or statements as to the improved conditions of modern surgery. Such improvement has been most striking and wonderful; but in old times surgery was carried on here and at the other hospitals in London with very good results, and we have not yet succeeded, nor probably ever shall, in conjuring away all the difficulties and dangers which beset serious cases.

He then turned to an examination of the list of amputations kept at the hospital, which now comprises the complete returns of thirty-six years, being more than 900 amputations. The first 500 had been tabulated by himself in two papers in the St. George's Hospital Reports, and the last 400 in a paper by Mr. Den' and Mr. Bull, still in manuscript. The object of his own papers was to show the great effect of the age of the patients upon the result of amputations, the large proportion of fatal cases in which death is due to causes independent of the operation, and the fact that pyæmia was the cause of almost the whole of the avoidable deaths. These conclusions were entirely supported by the later observers, who showed that the death-rate was still about double, after 30 years of age, what it was before that age; that the death-rate of all the cases had fallen from 31.6 to 21 per cent.; and that this is due to the diminution of the rate from pyæmia, which had fallen from 15 to 2 per cent. Amputations are now performed in cases of chronic albuminuria from protracted suppuration (of which a striking case was related); they are almost entirely free from any risk of secondary hæmorrhage; and they involve, as a rule, hardly any fever or suffering. This is due to drainage and to the antiseptic system. The management of a case of amputation under the old and under the modern method was described. 